MEI

II, vol. 2

$\mathrm{n}^{0} 2$

\title{
La Biblioteca del Tribunal Constitucional de España
}

\author{
Luis Ángel García Melero \\ Documentalista del Tribunal Constitucional
}

\section{Resumen}

Se exponen el marco jurídico y las competencias del Tribunal Constitucional de España así como la adscripción orgánica de su biblioteca. Las atribuciones legales de la institución y las necesidades informativas de los usuarios a los que atiende, configuran el contenido de la colección centrada en el derecho, legislación y jurisprudencia española, comunitaria e internacional. Se analizan las bases de datos bibliográficos y de autoridades y se exponen los principales servicios bibliotecarios prestados a los lectores. Por último, se describen los recursos humanos, técnicos y el espacio ocupado por la biblioteca en la sede del Tribunal Constitucional.

\section{Palabras clave}

Tribunal Constitucional; Biblioteca; Bibliotecas jurídicas; España.

The Library of the Constitutional Court of Spain

Abstract

The legal framework and powers of the Constitutional Court of Spain and the organic assignment of their library. The legal powers of the institution and the information needs of users it serves, make up the contents of the collection, focused on law, Spanish law and jurisprudence, and international community. The bibliographic and authorities' databases are analyzed, and the main services provided to library readers exposed. Finally, the human, technical and space occupied by the library at the headquarters of the Constitutional Court are described.

\section{Keywords}

Constitutional Court; Library; Law Libraries; Spain.

\section{Introducción}

Cuando me incorporé a trabajar en la biblioteca del Tribunal Constitucional de España (TCE en lo sucesivo) en el mes de febrero de 2010, me percaté de que disponía de una importante colección, sobre todo si tenemos en cuenta que la institución sólo tiene 30 años de existencia. También me di cuenta de que apenas era conocida, incluso en el ámbito español, tal vez por la suma especialización de la entidad.

Asimismo percibí que su base de datos bibliográficos no se adecuaba exactamente a los estándares existentes. Este hecho podría dificultar cualquier programa cooperativo, aunque se circunscribiera a las bibliotecas y centros de documentación del Poder Judicial, y la independencia de los datos de la aplicación informática empleada. Luego he ido conociendo las causas de esta adaptación de las normas bibliográficas y de informática documental. Básicamente podemos 
enumerar cinco motivos: $1^{\mathrm{a}}$ ) la insuficiente formación de la mayoría del personal de la biblioteca $\mathrm{o}$, al menos, no lo bastante actualizada, en documentación, bibliografía y biblioteconomía, $2^{\text {a }}$ ) la migración de distintas programas informáticos y de una a otra versión de un software, $3^{\mathrm{a}}$ ) la influencia de las bases de datos legales y de jurisprudencia $4^{\mathrm{a}}$ ) la consideración de la biblioteca como una unidad al servicio casi exclusivo de los usuarios internos y $5^{\mathrm{a}}$ ) las necesidades específicas de los lectores y de su entorno profesional. Poco a poco me fui haciendo más inteligente $\mathrm{y}$, por lo tanto, más flexible: todavía continúo estudiando la forma de compatibilizar las normas bibliográficas internacionales, las peculiaridades de la materia y las demandas precisas de los usuarios a quienes me debo.

También me llamó la atención la asiduidad con la que los Letrados y Magistrados acudían a la biblioteca para que se les facilitara bibliografía, jurisprudencia y legislación, antes de empezar a estudiar cualquier recurso aceptado a trámite. Pienso que la consideran un medio sustancial para actualizar sus conocimientos y para comparar casos similares presentados y resueltos en otros países y en otras jurisdicciones internacionales y nacionales.

Para solventar la falta de conocimiento de la biblioteca del TCE, me propuse escribir un artículo, aunque en él expresara mis opiniones y no las de la institución.

\section{Marco jurídico y competencias}

El TCE, intérprete supremo de la Constitución, se rige por el Título IX, artículos 159 a 165, de la Constitución Española de 1978, por la Ley Orgánica 2/1979, de 3 de octubre, y las modificaciones introducidas a la misma por las Leyes Orgánicas 8/1984, 4/1985, 6/1988, 7/1999, 1/2000, 6/2007, 1/2010, de 20 de febrero y 8/2010.

De acuerdo con esta legislación, podemos sintetizar las competencias del Tribunal Constitucional en las siguientes atribuciones:

1. Controlar la constitucionalidad de las leyes del Estado y de las Comunidades Autónomas planteadas a través del recurso y de la cuestión de inconstitucionalidad.

2. Resolver los recursos de amparo por violación de los derechos y libertades expuestos en el art. 53.2 de la Constitución en su condición de órgano jurisdiccional superior en materia de garantías constitucionales y último garante de los derechos y libertades fundamentales reconocidas en la Constitución.

3. Solucionar los conflictos constitucionales surgidos entre el Estado y una o más Comunidades Autónomas, entre dos o más Comunidades Autónomas entre sí o entre órganos constitucionales del Estado.

4. Resolver los conflictos en defensa de la autonomía local, promovidos por municipios y provincias, contra leyes o normas con rango de leyes estatales o autonómicas, que lesionen la autonomía local garantizada por la Constitución. 
5. Efectuar el control previo de constitucionalidad de tratados internacionales, a requerimiento del Gobierno, del Congreso o del Senado para evitar la integración de normas internacionales contrarias a la Constitución en el Derecho español.

6. Llevar a cabo anulaciones en defensa de la jurisdicción del Tribunal, a iniciativa del Tribunal y contra cualquier acto o resolución que menoscabe su jurisdicción.

7. Conocer los recursos interpuestos contra las Normas Forales fiscales de los Territorios de Álava, Guipúzcoa y Vizcaya y resolver las cuestiones que se susciten con carácter prejudicial por los órganos jurisdiccionales.

\section{Adscripción orgánica}

Conforme a lo establecido en el artículo 33 del Reglamento de organización y personal del Tribunal Constitucional, posteriormente modificado por los Acuerdos de 5 de octubre de 1994, de 8 de septiembre de 1999, de 27 de febrero de 2001, de 19 de diciembre de 2002 , de 14 de mayo de 2003 , de 31 de marzo de 2008 y de 28 de abril de 2010, la biblioteca del TCE está adscrita al Servicio de Estudios, Biblioteca y Documentación dependiente de la Secretaría General de la institución. Las competencias de este Servicio, cuya Jefatura corresponde a un Letrado designado por el Presidente, son

1. La programación y elaboración de cuantos trabajos en materia doctrinal, jurisprudencial y legislativa se estimen necesarios.

2. La prestación del servicio de documentación y la gestión de la Biblioteca del Tribunal.

3. Elaborar y ejecutar los planes de publicaciones del Tribunal.

\section{Usuarios}

Como sucede con otras unidades de información especializadas, las necesidades informativas de los usuarios determinan la planificación y organización de los procesos y servicios. La biblioteca del TCE es, fundamentalmente, un instrumento de ayuda para la realización de las funciones de los Magistrados y Letrados que trabajan o han trabajado en ella, aunque está abierta a todo el personal de la institución. También pueden utilizar sus fondos y servicios los letrados extranjeros, que se encuentren en una estancia temporal en el TCE, los investigadores y los becarios.

La Instrucción 3/2000, de 17 de noviembre, especifica que las autorizaciones para que los investigadores accedan a la biblioteca, serán concedidas por el Letrado Jefe del citado Servicio durante un periodo no superior a quince días prorrogable por igual plazo. Un requisito previo a la autorización, es el aval de un Magistrado activo o emérito, del Secretario General del TCE, de un Letrado o antiguo Letrado, o de un profesor de Universidad. La biblioteca es, pues, una unidad con acceso restringido como sucede en otros centros especializados similares al TCE. 
En la actualidad hay unos 204 usuarios internos registrados en la base de datos de lectores.

\section{Amplitud temática y tipología documental de la colección}

Si repasamos las competencias del Tribunal, comprenderemos que el contenido de las publicaciones no versa únicamente sobre derecho y jurisdicción constitucional, como en un principio pudiera parecer. La diversidad temática de los recursos de inconstitucionalidad y de amparo que se pueden presentar, requieren una amplia colección sobre todas las ramas de las ciencias jurídicas.

Debería ser, por lo tanto, una biblioteca especializada en derecho, legislación y jurisprudencia española y extranjera sin olvidar el derecho internacional y el comunitario que España, como estado miembro de la Unión Europea, está obligada a trasponer en sus normas legales.

Contrastemos la teoría con la realidad. El análisis bibliométrico del número de referencias existente de cada grupo de la clasificación bibliográfica utilizada en la biblioteca del TCE, ofrece el siguiente resultado. Hay más de 2000 publicaciones de las siguientes materias expuestas en orden descendente: Derechos fundamentales, Derecho constitucional, Derecho penal, Derecho administrativo, Derecho comunitario, Jurisdicción constitucional, Ciencia política, Organización territorial del Estado, Derecho del trabajo, Filosofía del derecho, Derecho civil, Derecho tributario, Derecho procesal penal, Historia de las ideas y Administración de justicia.

El siguiente cuadro muestra los principales asuntos, desde el punto de vista cuantitativo, de los que existen más de 800 registros en la base de datos bibliográficos de la biblioteca del TCE: 
MEI, II, Vol. 2, nº 2, pág. 51

\begin{tabular}{|c|c|}
\hline Materia & $\begin{array}{c}\text { Número de } \\
\text { referencias bibliográficas }\end{array}$ \\
\hline Derechos fundamentales & 11561 \\
\hline Derecho constitucional & 10115 \\
\hline Derecho penal & 6685 \\
\hline Derecho administrativo & 6641 \\
\hline Derecho comunitario & 6411 \\
\hline Jurisdicción constitucional & 5242 \\
\hline Ciencia política & 3719 \\
\hline Organización territorial del Estado & 3678 \\
\hline Derecho del trabajo & 3021 \\
\hline Filosofía del derecho & 2763 \\
\hline Derecho civil & 2699 \\
\hline Derecho tributario & 2526 \\
\hline Derecho procesal penal & 2509 \\
\hline Historia de las ideas & 2210 \\
\hline Administración de justicia & 2100 \\
\hline Relaciones laborales & 1990 \\
\hline Derecho procesal civil & 1981 \\
\hline Derecho parlamentario & 1798 \\
\hline Historia de España & 1795 \\
\hline Derecho internacional público & 1639 \\
\hline Derecho & 1518 \\
\hline Derecho procesal & 1435 \\
\hline Derecho mercantil & 1389 \\
\hline Derecho procesal administrativo & 1256 \\
\hline Seguridad social & 1117 \\
\hline Administración local & 1077 \\
\hline Derecho de familia & 1053 \\
\hline Derecho internacional & 964 \\
\hline Historia del derecho & 931 \\
\hline
\end{tabular}

Tabla 1. Amplitud temática de la base de datos bibliográficos

La tipología documental comprende materiales impresos y digitales, tanto en soporte físico como accesibles a través de las redes de telecomunicaciones. Los libros y publicaciones seriadas en papel conviven con los editados en CD-ROM, 
DVD, las bases de datos remotas y las revistas disponibles en Internet por ser de dominio público o porque la suscripción en papel facilita el acceso a la versión en línea. En este sentido, como la mayoría de las bibliotecas actuales, la del TCE es también una biblioteca híbrida en la que coexisten los entornos analógicos y digitales.

Según muestra el Cuadro 2, a finales del mes de diciembre de 2010, la colección física está formada por 62.296 títulos de los que 60.648 corresponde a libros, 1125 a revistas y 523 a CD-ROM, DVD-ROM y memorias USB.

\begin{tabular}{|c|l|c|}
\hline Colección & \multicolumn{1}{|c|}{ Tipo de documentos } & $\begin{array}{c}\text { Número de } \\
\text { títulos }\end{array}$ \\
\hline Física & Libros & 60.648 \\
\hline & Revistas & 1125 \\
\hline Virtual & Publicaciones electrónicas en soporte físico & 523 \\
\hline & Bases de datos & 16 \\
\hline & Revistas & 134 \\
\hline & $\begin{array}{l}\text { Artículos de revistas y colaboraciones de } \\
\text { obras colectivas digitales }\end{array}$ \\
\hline & $\begin{array}{l}\text { Bases de datos bibliográficos, legales y de } \\
\text { jurisprudencia de dominio público }\end{array}$ & Sin cuantificar \\
\hline
\end{tabular}

Tabla 2. Las colecciones de la biblioteca del TCE

La mayoría de estas publicaciones están editadas a partir de 1980, año en el que empieza a funcionar el TCE y su biblioteca. No obstante, cabe destacar el importante crecimiento de la colección en la primera década del siglo XXI. Las obras anteriores a 1980 se han comprado o han sido donadas por Letrados y Magistrados del Tribunal. El Cuadro 3 muestra la distribución cronológica de las publicaciones.

\begin{tabular}{|l|r|}
\hline $\begin{array}{c}\text { Periodo } \\
\text { cronológico }\end{array}$ & $\begin{array}{c}\text { Número de } \\
\text { publicaciones }\end{array}$ \\
\hline Siglo XVIII & 7 \\
\hline Siglo XIX & 170 \\
\hline $1900-1925$ & 207 \\
\hline $1926-1950$ & 367 \\
\hline $1951-1975$ & 3015 \\
\hline $1976-2000$ & 61033 \\
\hline $2001-2010$ & 44720 \\
\hline
\end{tabular}

Tabla 3. Amplitud cronológica 
La colección digital o virtual la componen 16 bases de datos contratadas. Además hay un número difícil de cuantificar de accesos a bases de datos legales de dominio público que posibilitan recuperar las normas jurídicas de diferentes administraciones estatales, autonómicas o regionales y locales. Otras, también de dominio público, permiten la búsqueda y recuperación de las sentencias de distintos tribunales nacionales, comunitarios e internacionales. Junto a ellas se encuentran las direcciones electrónicas de agregadores de objetos digitales, repositorios institucionales, bibliotecas digitales y los catálogos de las principales bibliotecas españolas y extranjeras que permiten completar la información bibliográfica existente en la base de datos y colección del TCE.

La colección virtual dispone, además, de 134 títulos de revistas jurídicas gratuitas o cuyos contenidos se pueden consultar por Internet por haber suscrito la versión en papel. Por último, los usuarios pueden acceder desde la intranet institucional, además de a los recursos enumerados, a una colección de unos 1.827 artículos de revistas y de colaboraciones editadas en obras colectivas. Corresponden, en su casi totalidad, a publicaciones descargadas de revistas de dominio público o que se han escaneado de la versión impresa, para fines de investigación y estudio, con el fin de atender las demandas de los lectores. El texto completo de los artículos también se puede visualizar desde el catálogo en línea de acceso público (OPAC), pues el registro bibliográfico y el documento digital se encuentran relacionados.

La selección de los materiales bibliográficos a comprar y de los recibidos como donativos, la realiza el Letrado Jefe del Servicio de Estudios, Biblioteca y Documentación. Los Magistrados, Letrados y algunos miembros del personal del TCE pueden formular propuestas de adquisición.

La media anual de libros adquiridos durante el periodo 2005-2009 es de 3691 títulos. En el 2010 se han suscrito 416 títulos de publicaciones en serie.

\section{La base de datos bibliográfica}

El sistema integrado de gestión bibliotecaria utilizado por la biblioteca del TCE es la versión 7 de Absys desarrollada por la empresa española Baratz, Servicios de Teledocumentación. Permite llevar a cabo la informatización de los diferentes subsistemas o módulos bibliotecarios: adquisiciones, series, catalogación y clasificación, ficheros de autoridades, circulación y consulta en línea del catálogo. Los registros bibliográficos se encuentran redactados conforme a las Reglas de Catalogación del Ministerio de Educación y Cultura (1999), basadas en las ISBD, y codificados en formato Ibermac (Biblioteca Nacional, 2001).

Como he apuntado en la introducción, la biblioteca del TCE ha realizado algunas interpretaciones de esta normativa, que se está revisando para una mayor adecuación a los estándares internacionales. Existe la previsión a corto plazo de migrar al formato MARC21 y a la ISBD Consolidada 
La base de datos bibliográfica es mucho mayor que la colección. Ello se debe a que se lleva a cabo la catalogación analítica o vaciado de los artículos de revistas y de las colaboraciones en obras colectivas que se consideran que pueden interesar a los usuarios. La expresión "obras colectivas" comprende, entre otras, las actas de congresos, seminarios, etc., los homenajes y los libros escritos por más de tres autores, cuyos capítulos están redactados por uno o más especialistas. Estas últimas ascienden a unos 10.145 títulos (el 16’72 \% del total de libros).

La tabla 4 muestra el número de registros existentes de cada tipo documental en la base de datos bibliográficos y el porcentaje que representan en relación con la totalidad. Las cifras se refieren, como en el caso de los títulos de las colecciones, a finales del mes de diciembre del 2010:

\begin{tabular}{|l|r|r|}
\hline \multicolumn{1}{|c|}{ Tipos de documentos } & Número de registros & Porcentaje \\
\hline Libros & 60648 & $53^{\prime} 65$ \\
\hline Revistas & 1125 & I'00 $^{\prime}$ \\
\hline Artículo de revistas & 36054 & $31^{\prime} 89$ \\
\hline Colaboraciones en obras colectivas & 15196 & $13^{\prime} 44$ \\
\hline Total & 113023 & $99^{\prime} 98$ \\
\hline
\end{tabular}

Tabla 4.Tipos de registros existentes en la base de datos bibliográficos

La media anual de registros bibliográficos creados durante el periodo 2005-2009 es de 5645. El desglose de esta cifra es el siguiente: 3048 registros de libros, 26 de publicaciones periódicas, 937 de colaboraciones en obras colectivas y 1634 de artículos de revistas.

El número total de catalogaciones analíticas (51.250) es ligeramente inferior al de monografías (60.648). Este hecho se puede deber en parte a que no se "vacían" la totalidad de los artículos y de las colaboraciones publicadas en las revistas y obras colectivas que ingresan en la biblioteca, sino sólo las que se consideran más pertinentes para los cometidos del TCE. Una mayor cifra de catalogaciones analíticas se correspondería de manera más adecuada con las funcionalidades de las bibliotecas especializadas que han de procurar el control, difusión y acceso a la información más actual y específica.

El análisis de la procedencia geográfica de las publicaciones que muestra el Cuadro 5 , pone de manifiesto que la bibliografía española ( $80^{\prime} 50 \%$ de los títulos disponibles en la base de datos bibliográficos) prevalece sobre la extranjera (19'49\%). Los países más representados en esta última son, por este orden, Italia, Alemania, Reino Unido, Francia, Estados Unidos, Bélgica, México, Argentina, Holanda, Suiza, Austria y un grupo de otras naciones de las que hay menos de 200 títulos de cada una. 
$\mathrm{Si}$ examinamos estos resultados por cada uno de los tipos de materiales bibliográficos, se llega a las siguientes conclusiones:

1. Predominan los libros editados en España, a los que siguen, por este orden, los publicados en Italia, Alemania, Reino Unido, Estados Unidos, Francia, Bélgica, Argentina, Holanda, México, Suiza y Austria.

2. Las revistas españolas destacan de forma evidente. Las siguen, a gran distancia, las editadas en Alemania, Italia, Francia, Estados Unidos, Reino Unido, Bélgica, Argentina, México y Holanda. La aparente inconsistencia de que no haya ninguna publicación periódica austriaca ni suiza con la existencia de artículos analizados editados en Austria y Suiza, se puede deber a un error en la codificación del país editor o en el tipo de material bibliográfico. Otra posible causa es que se trate de un número monográfico de una publicación periódica, que se adquirió por la especialidad de su temática, pero que se procesó como un libro.

3. En el caso de los artículos de publicaciones periódicas, el orden de los libros se ve ligeramente modificado. Los editados en revistas españolas son seguidos por los aparecidos en revistas italianas, francesas, alemanas, inglesas, belgas, norteamericanas, mexicanas, holandesas, argentinas, austriacas y suizas.

4. Las colaboraciones de obras colectivas españolas son seguidas a gran distancia por las italianas, alemanas, mexicanas, belgas, francesas, inglesas, argentinas, suizas, norteamericanas, austriacas y holandesas.

\begin{tabular}{|c|c|c|c|c|c|}
\hline País & Libros & Revistas & $\begin{array}{l}\text { Artículos de } \\
\text { revistas }\end{array}$ & $\begin{array}{c}\text { Colaboraciones } \\
\text { en obras } \\
\text { colectivas }\end{array}$ & $\begin{array}{c}\text { Total } \\
\text { absoluto }\end{array}$ \\
\hline Alemania & 2483 & 64 & 986 & 791 & 4326 \\
\hline Argentina & 444 & 10 & 36 & 62 & 552 \\
\hline Austria & 97 & O & 28 & 47 & 172 \\
\hline Bélgica & 457 & 18 & 268 & 239 & 982 \\
\hline España & 47617 & 773 & 30630 & 11969 & 90993 \\
\hline Estados Unidos & 1246 & 24 & 155 & 50 & 1475 \\
\hline Francia & 1164 & 51 & 1019 & 172 & 2406 \\
\hline Holanda & 307 & 6 & 48 & 32 & 393 \\
\hline Italia & 3694 & 60 & 2085 & 920 & 6760 \\
\hline México & 305 & 7 & 120 & 401 & 833 \\
\hline Otros países & 804 & 90 & 205 & 334 & 1433 \\
\hline Reino Unido & 1913 & 22 & 454 & 122 & 2511 \\
\hline Suiza & 117 & O & 20 & 57 & 194 \\
\hline TOTAL & 60648 & 1125 & 36054 & 15196 & 113030 \\
\hline
\end{tabular}

Tabla 5. Países de edición de los documentos 


\section{La base de datos de autoridades}

Los registros de las bases de datos de autoridades están redactados conforme a los epígrafes de las Reglas de Catalogación del Ministerio de Cultura dedicados a los puntos de acceso de personas físicas y jurídicas, congresos y títulos uniformes. Internamente están codificados de acuerdo con el formato Ibermarc para autoridades (Biblioteca Nacional, 1999). Su representación, se adecúa a las Directrices para asientos de autoridad y referencia (GARE) de la IFLA para personas, entidades, congresos y títulos (1993). En el caso de los asuntos, se siguen las directrices correspondientes a materias (SGARE) de la IFLA (1995) y las normas ISO relacionadas con la elaboración de tesauros. También en este caso existe la previsión de adoptar a corto plazo el formato MARC21 para autoridades.

Como en la base de datos bibliográficos, también en este caso se han realizado adaptaciones, que están siendo revisadas para adecuarlas a la normativa internacional.

Los descriptores, más de 3000, utilizados para denominar los conceptos sobre los que versan las publicaciones, han sido elaborados por dos documentalistas con formación en ciencias jurídicas. Aunque en muchos casos existen las relaciones propias de un tesauro (equivalencia, asociativas y jerárquicas), todavía hay algunas disciplinas en las que faltan todas o determinadas conexiones. Por ello preferimos referirnos a este lenguaje documental como listado de descriptores en lugar de tesauro.

Una de las peculiaridades más relevantes de la biblioteca del TCE, es la forma de indizar las leyes y sentencias de los distintos tipos de tribunales sobre las que tratan una parte muy significativa de las publicaciones referenciadas en la base de datos bibliográficos. Para hacerlo se emplea la manera abreviada de ser citada la norma legal en el diario oficial de la administración que la ha elaborado y en el que se publica. Lo mismo sucede con la jurisprudencia: la sentencia se identifica por su número de referencia. Estas formas abreviadas de citar las leyes españolas y extranjeras y las sentencias de los tribunales de cualquier jurisdicción y ámbito geográfico, es lo que se denomina "identificador".

Así, un artículo que analizara y comentara la sentencia del Tribunal Constitucional 45/2010, Cuestión de inconstitucionalidad 5003-2007. Planteada por el Juzgado de lo Penal núm. 2 de Albacete en relación con los artículos 148.4 y 153.1 del Código penal en la redacción de la Ley Orgánica 1/2004, de medidas de protección integral contra la violencia de género, además de los descriptores que identifican los asuntos sobre los que versa y el ámbito geográfico, se añaden los "identificadores" Código Penal 1995. Art. 148.4, Código Penal 1995. Art. 153.1, LO 1/2004 y STC 45/2010 en lugar de la forma bibliográfica estipulada por las normas bibliográficas: España. Código penal, 1995. Art. 148.4, España. Código penal, 1995. Art. 153.1, España. Ley Orgánica de medidas de protección integral contra la violencia de género, 2004 y España. Tribunal Constitucional. STC 45/2010...La eventual homonimia de los 
identificadores se rompe grabando el nombre geográfico del país que ha elaborado la norma legal en el campo correspondiente.

Los motivos que, al parecer, han inducido a los documentalistas del TCE a adoptar estos descriptores han sido las siguientes:

1. La conveniencia de utilizar un lenguaje más directo y sintético.

2. La carencia de ejemplos de legislación y jurisprudencia contemporánea en las Reglas de Catalogación.

3. La influencia de las bases de datos legales y jurídicos.

4. El influjo de la denominación de las leyes en los boletines oficiales y de los números de las sentencias promulgadas por los distintos tribunales.

5. El impacto de las normas de citación de la legislación y jurisprudencia utilizadas en la bibliografía jurídica nacional y extranjera.

6. La influencia de algunos estándares de estilo para la presentación de las resoluciones de tribunales y de las convenciones para la elaboración de cualquier tipo de documento de las instituciones, órganos y servicios de la Unión Europea (2011).

7. Las demandas informativas de los usuarios, que solicitan bibliografía, legislación y jurisprudencia por el tipo de disposición legal y su número de orden dentro de un año o por el número de referencia de la sentencia.

La crítica por mi parte a esta práctica se refiere al posible impacto que pueda tener en posibles y deseables proyectos cooperativos, al menos, con otras bibliotecas judiciales y especializadas en derecho. También advierto sobre el uso inadecuado de los descriptores geográficos, destinados para indicar la localidad sobre la que versa una publicación, que se confunde con la jurisdicción en la que se ha elaborado y es aplicable la legislación y/o jurisprudencia. Asimismo pongo reparos sobre el campo o atributo del formato Ibermarc de registros bibliográficos que se viene empleando para su codificación, asumiendo que esta forma es un título uniforme: 730, Encabezamiento secundario, Título uniforme, en lugar de 630. Encabezamiento secundario de materia, Título uniforme. Quizá puedan solventarse las especificaciones normativas y las prácticas locales mediante una referencia en la base de autoridades de una a otra forma.

En la actualidad, el volumen de registros de autoridades y de los bibliográficos asociados a cada autoridad, que habría que modificar, requiere un esfuerzo importante. Esta práctica, además de que en ella se graban los títulos de las revistas, es la que explica que existan tantas autoridades del tipo "Título uniforme" en la base de datos de autoridades según muestra el Cuadro 6. Las cifras deben ser consideradas orientativas, pues a diario se crean y modifican registros, como prueban que la media anual de registros creados durante el periodo 2005-2009 fuera de 1863 y de modificados, 2124. 
MEI, II, Vol. 2, nº 2, pág. 58

\begin{tabular}{|l|r|}
\hline \multicolumn{1}{|c|}{ Tipo de autoridad } & Número de registros \\
\hline Personas & 36483 \\
\hline Entidades & 1416 \\
\hline Congresos & 1148 \\
\hline Títulos uniformes & 6182 \\
\hline Materias & 3207 \\
\hline Nombres geográficos & 300 \\
\hline Término género/forma & 50 \\
\hline Subdivisión de materias & 3 \\
\hline Subdivisiones geográficas & 1 \\
\hline Subdivisiones cronológicas & 24 \\
\hline Subdivisiones de forma & 13 \\
\hline Total & 48827 \\
\hline
\end{tabular}

Tabla 6. Registros de autoridades

\section{Servicios bibliotecarios}

La biblioteca del TCE facilita a sus usuarios los servicios bibliotecarios tradicionales en esta clase de centros: difusión de boletines de novedades, búsquedas delegadas, consulta en sala, préstamo de libros, reproducción de partes de documentos y gestión de préstamos interbibliotecarios.

\section{Difusión de boletines de novedades}

Se editan y distribuyen, a través de la intranet institucional, tres boletines que informan de las novedades bibliográficas, de los sumarios de los números de las revistas ingresados durante el último mes y de las leyes y sentencias más relevantes publicadas asimismo en el último mes. En la actualidad se está pensando en rediseñar estos productos. El propósito es editar un boletín regular que dé cuenta de los últimos libros, artículos de revistas y colaboraciones en obras colectivas procesados durante los últimos quince o treinta días.

Además de este listado de interés general para todos los Magistrados y Letrados, se está estudiando la elaboración y distribución de boletines de difusión selectiva de información (DSI) con las referencias bibliográficas de los perfiles temáticos que interesen a cada usuario. Estos boletines se remitirían directamente al buzón de correo electrónico del lector. Las referencias bibliográficas irían acompañadas de enlaces al texto completo de cada artículo de revista de forma que pudieran imprimirlos o descargarlos en su ordenador personal.

También se está analizando la temática de las bibliografías dinámicas a las que podrán acceder los usuarios desde la página de acogida del nuevo OPAC. Las relativas a la jurisdicción constitucional española, autos, declaraciones de 
inconstitucionalidad, sentencias comentadas y recursos de amparos del TCE sin duda estarán entre los asuntos elegidos. De esta forma, los Magistrados y Letrados se podrán informar de las últimas publicaciones ingresadas en la base de datos que versen sobre las materias enumeradas-

\section{Búsquedas delegadas}

Los usuarios pueden consultar desde sus puestos de trabajo informáticos los recursos informativos internos y externos que la biblioteca pone a su disposición. Los primeros están conformados por el catálogo en línea, las bases de datos de artículos de revistas y de obras colectivas, la colección digital y las revistas en línea accesible a través de Internet. Los recursos externos están constituidos por las bases de datos legales y de jurisprudencia, contratadas o disponibles en la Web de forma gratuita, y por los catálogos de otras bibliotecas, generales y especializadas, que pueden ser consultados por Internet.

No obstante, la biblioteca ofrece el servicio de realizar búsquedas en todos los recursos informativos sobre los tema de interés para los Magistrados y Letrados. El resultado, en su forma más amplia, es un listado con las referencias bibliográficas de los documentos, existentes en la biblioteca del TCE y/o en bibliotecas externas, que satisfacen la demanda, A ellos se añaden las disposiciones legales y las sentencias dictadas sobre el mismo asunto u otros similares por otros tribunales nacionales o extranjeros. A posteriori se remite al usuario las publicaciones que considera más pertinentes. En la mayoría de las ocasiones, el listado se reduce a registros bibliográficos de las obras disponibles en la biblioteca del TCE, de leyes o de jurisprudencia.

\section{Consulta en sala}

Este servicio consiste en la posibilidad que tienen los letrados extranjeros, investigadores autorizados y los becarios a consultar en la sala de lectura las publicaciones de la biblioteca. También se refiere a la lectura puntual de las obras de referencia, de los últimos números recibidos de las revistas en papel y de los libros procesados en los últimos meses.

La colección de referencia está formada por enciclopedias y diccionarios generales, especializados y bilingües, por grandes tratados históricos, atlas, bibliografías y directorios. Además alberga una importante colección con la edición más reciente de textos legales y los volúmenes con la jurisprudencia de distintos tribunales comunitarios, nacionales y extranjeros. A corto plazo hay el proyecto de facilitar un mayor acceso a las versiones electrónicas de las obras de referencia reduciendo al máximo las disponibles en soporte papel. Este proyecto va a obligar a ampliar la tipología de recursos informativos accesibles a través de la intranet institucional y a contratar aquellos que no sean de dominio público. 


\section{Préstamos de libros}

No existe ninguna limitación cuantitativa ni temporal de los libros que se pueden prestar a los Magistrados y Letrados. La única salvedad es que, cuando un usuario precisa una monografía que está prestada, el que la tiene prestada ha de devolverla a la mayor brevedad posible. En ningún caso se revela ni la identidad del prestatario ni del peticionario por razones de intimidad y confidencialidad y para evitar que la biblioteca pierda el control de la obra en cuestión. Antes de que un usuario deje de desempeñar sus funciones en el TCE, se le remite un listado de las obras que tiene prestadas para que proceda a su devolución.

Aun no se ha planteado el préstamo de libros electrónicos o e-books, como ya viene siendo habitual en las bibliotecas universitarias.

Hay, además, préstamos o depósitos de publicaciones a las distintas Salas y secciones en los que se estructura el TCE. Estas obras son, por lo general, compilaciones legislativas, diccionarios bilingües y de la lengua española, es decir: instrumentos de trabajo cuya consulta es frecuente.

\section{Reproducciones de partes de documentos}

Cuando un lector solicita una reproducción de un artículo de revista o de una colaboración en una obra colectiva, se comprueba si ya existe en la colección digital, por haber sido solicitada previamente. En caso de que así sea, y si el usuario no se ha percatado de que la podía haber descargado desde el OPAC, se le remite por correo electrónico adjuntándole el archivo correspondiente. Si no se cuenta con la versión digital, se verifica si se ha editado en una revista en línea o si está disponible en algún repositorio externo. En el supuesto de que así fuera, se remite una copia del artículo por correo electrónico al lector y se guarda otra en la colección digital que, posteriormente, se identifica, describe y se asocia al registro bibliográfico. Cuando no hay una versión electrónica, se escanea, se envía una copia al peticionario, se guarda otra en la colección digital y se realizan las tareas ya mencionadas.

Este procedimiento permite atender con agilidad las demandas de los usuarios, que, además, pueden ir formando su colección digital en las memorias masivas (disco duro, USB, etc.) de su sistema informático. También posibilita que la biblioteca del TCE vaya incrementando su "biblioteca digital" y mejorando los tiempos de repuesta en el suministro de documentos.

\section{Préstamo interbibliotecario}

El servicio de préstamo interbibliotecario prácticamente no existe. Las peticiones que se tramitan a otras bibliotecas, se realizan más a título personal que institucional. Lo mismo sucede con las escasas solicitudes de reproducciones de partes de publicaciones que se reciben de otros centros españoles. Este hecho pone de manifiesto la utilización cada vez mayor por las bibliotecas de las revistas de 
dominio público y de los repositorios de documentos digitales para atender estas necesidades. También puede revelar la calidad de la colección del TCE y la falta de conocimiento de la misma por otros organismos. Esto último se debe, sin duda, a la escasa información disponible y a la especialización de la institución.

\section{Otros servicios}

Otra actividad que se lleva a cabo consiste en la explicación, más o menos pormenorizada según el tiempo disponible, de las funciones realizadas por la biblioteca del Tribunal Constitucional a las visitas colectivas guiadas.

\section{Recursos humanos, técnicos y económicos}

\section{Recursos humanos}

El personal adscrito a la biblioteca se rige por el Reglamento del Tribunal Constitucional y otras disposiciones de éste y, en lo no previsto en ellas, por la normativa aplicable suplementariamente al personal funcionario y laboral de las administraciones públicas. Por otra parte, los puestos y sus funciones se contienen en la relación de puestos de trabajo (RPT) del Tribunal.

A finales del mes de diciembre de 2010, trabajaban en la biblioteca quince personas. Cuatro de ellas, denominadas documentalistas, se encargan del proceso técnico del análisis de los artículos de revistas y de las colaboraciones en obras colectivas. También se ocupan de la revisión de la catalogación de las monografías, de su indización y clasificación, de la gestión de los ficheros de autoridades, del mantenimiento de las páginas especializadas de la intranet y de la colección virtual. Por último llevan a cabo las búsquedas bibliográficas delegadas, distribuyen las peticiones de préstamo de libros y de reproducciones, elaboran el boletín de documentación, supervisan los correspondientes a sumarios de publicaciones periódicas y novedades bibliográficas. También atienden a las visitas colectivas informando sobre la biblioteca.

Un grupo de cinco trabajadores, a medio camino entre las funciones desarrolladas por los auxiliares y ayudantes de bibliotecas de otros centros de las administraciones públicas, efectúan la catalogación de las monografías y de las revistas, el registro de los números ingresados de publicaciones seriadas y tramitan las peticiones de los usuarios.

Seis trabajadores, asimilables a auxiliares administrativos, llevan a cabo el control económico administrativo de las adquisiciones, la gestión de la información y documentación relacionada con la ubicación física de los ejemplares y su posterior circulación y graban los contenidos de los sumarios de las publicaciones periódicas y de los índices de los libros colectivos en bases de datos especializadas. También se ocupan de redactar los registros bibliográficos analíticos en el sistema integrado de gestión bibliotecaria así como de la edición, composición tipográfica y distribución de los boletines de novedades. 
Los ordenanzas del Tribunal Constitucional adscritos al servicio en la biblioteca, llevan a cabo las tareas de localización y restitución a los depósitos de las publicaciones que circulan, la realización material de las reproducciones y la distribución de los documentos a los usuarios que las han solicitado.

La plantilla, aun a falta de que, al parecer, se cubra el puesto de trabajo de responsable o Documentalista Jefe, es, en mi opinión más que suficiente. Adolece, tal vez, de una actualización de conocimientos y de una definición precisa de las funciones que cada miembro debe desempeñar. Otra de las críticas constructivas que realizo es la necesidad de revisar y reformar algunos procedimientos, entre otros, la unificación de las tareas de descripción bibliográfica e indización en un mismo trabajador y el establecimiento de proyectos cooperativos con otros centros similares para racionalizar los procesos técnicos y algunos servicios bibliotecarios.

También sería aconsejable, reemplazar las grabaciones de los sumarios de las revistas y de los índices de las obras colectivas, por la digitalización de los mismos o por el establecimiento de enlaces a direcciones electrónicas donde ya están disponibles. Estas medidas permitirían redefinir las funciones del personal y dedicarles a trabajos de una utilidad más inmediata para los usuarios y, a mi juicio, deberían reflejarse en la RPT.

\section{Recursos técnicos}

Además del puesto informático dedicado a cada trabajador y de las impresoras asociadas, todos ellos conectados con el ordenador servidor donde se alberga la aplicación informática y los datos, la biblioteca dispone de unas cuatro fotocopiadoras, una de las cuales se emplea, además, para el escaneo de las reproducciones solicitadas.

Los programas informáticos utilizados son el ya mencionado Absys 7 del que se migrará a Absysnet, también de la misma empresa, a lo largo de 2011 y dos aplicaciones ad hoc para el vaciado de los contenidos de las revistas y libros colectivos y la edición del sumario o índice. Además se usa el software de gestión de contenidos de la intranet, el navegador Internet Explorer, la suite de Microsoft Office y Adobe Profesional o Estándar para la conversión de documentos a formato pdf.

Respecto al acceso a la base de datos bibliográficos de la biblioteca del TCE a través de Internet, no se ha considerado necesario debido a su carácter interno.

\section{Recursos económicos}

Los recursos económicos destinados a la adquisición de monografías, la suscripción de publicaciones seriadas, encuadernación de volúmenes de revistas y restauración de materiales bibliográficos antiguos son lo suficientemente amplios para comprar 
casi todo lo que se edita en España en ciencias jurídicas y una muestra significativa de la bibliografía extranjera.

\section{Espacio}

La biblioteca del Tribunal Constitucional ocupa espacio en cuatro zonas distintas de su sede en la calle Doménico Scarlatti de Madrid.

La primera zona está destinada a la Sala de lectura. En ella desempeñan sus funciones cuatro miembros de la plantilla y alberga, además de los puestos de lectura, la colección de referencia, los últimos números de las revistas recibidas y los libros procesados durante el último año aproximadamente.

La segunda alberga al personal dedicado a las adquisiciones, la catalogación, proceso final de los libros y a la grabación de los sumarios e índices. En ella trabajan nueve personas y hay metros lineales de estanterías suficientes para albergar los materiales que intervienen en las tareas que en ella se llevan a cabo.

En la planta principal de la sede del Tribunal, donde están alojadas las dos zonas anteriores, hay dos despachos destinados a otros tantos documentalistas donde desempeñan algunos de los trabajos enumerados más arriba.

Los depósitos de las revistas cerradas y en activo y de los libros anteriores al último año, incluidos los antiguos y de mayor valor (la denominada reserva), ocupan dos zonas de los sótanos del edificio. Todas las publicaciones son almacenadas y conservadas en estanterías tipo compactus.

Madrid, 31 de enero de 2011

\section{Bibliografía}

Biblioteca Nacional (1999). Formato IBERMARC para registros de autoridad. Biblioteca Nacional, Madrid.

Biblioteca Nacional (2001). Formato IBERMARC para registros bibliográficos. Biblioteca Nacional, Madrid.

Unión Europea (2011). Libro de estilo interinstitucional. Disponible en:

$<$ publications.europa.eu/code/es/es-000100.htm>

[Consulta: 3 de julio 2011].

Federación Internacional de Asociaciones de Bibliotecarios y Bibliotecas (IFLA) (1993). Directrices para las entradas de autoridad y referencia. ANABAD, Madrid.

Federación Internacional de Asociaciones de Bibliotecarios y Bibliotecas (IFLA) (1995). Directrices para los registros de autoridad y referencia de materia. ANABAD, Madrid. 
Ministerio de Educación y Cultura (1999), Reglas de Catalogación: edición nuevamente revisada. Ministerio de Educación y Cultura, Centro de Publicaciones: Boletín Oficial del Estado, Madrid.

\section{Disposiciones legislativas citadas en el texto}

España. Constitución Española. Disponible en:

< http://www.boe.es/a eboe/consultas/enlaces/documentos/ ConstitucionCASTELLANO.pdf>

[Consulta: 3 de julio 2011].

España. Ley Orgánica 2/1979, de 3 de octubre, del Tribunal Constitucional, Boletín Oficial del Estado, 5 de octubre 1979, No 239, pp. $23186-23195$.

España. Ley Orgánica 8/1984, de 26 de diciembre, por la que se regula el régimen de recurso en caso de objeción de conciencia, su régimen penal y se deroga el artículo 45 de la Ley Orgánica 2/1979, de 3 de octubre, del Tribunal Constitucional, Boletín Oficial del Estado, 28 de diciembre 1984, No 31 1, p. 37365.

España. Ley orgánica 4/1985, de 7 de junio, por la que se deroga el capítulo II del título IV de la Ley orgánica 2/1979, de 3 de octubre, reguladora del Tribunal Constitucional, Boletín Oficial del Estado, 8 de junio 1985, No 137,p. 17286.

España. Ley Orgánica 6/1988, de 9 de junio, por la que se modifican los artículos 50 y 86 de la Ley Orgánica 2/1979, de 3 de octubre, del Tribunal Constitucional, Boletín Oficial del Estado, 11 de junio 1988, No 140, p. 18314.

España. Ley Orgánica 7/1999, de 21 de abril, de modificación de la Ley Orgánica 2/1979, de 3 de octubre, del Tribunal Constitucional, Boletín Oficial del Estado, 22 de abril 1999, No 96, pp. 14922-14923.

España. Ley Orgánica 1/2000, de 7 de enero, de modificación de la Ley Orgánica 2/1979, de 3 de octubre, del Tribunal Constitucional, Boletín Oficial del Estado, 10 de enero 2000, No 8, p. 880.

España. Ley Orgánica 6/2007, de 24 de mayo, por la que se modifica la Ley Orgánica 2/1979, de 3 de octubre, del Tribunal Constitucional, Boletín Oficial del Estado, 25 de mayo 2007, No 125, pp. 22541-22547.

España. Ley Orgánica 1/2010, de 19 de febrero, de modificación de las leyes orgánicas del Tribunal Constitucional y del Poder Judicial, Boletín Oficial del Estado, 20 de febrero 2010, No 45, pp. 16641-16644.

España. Ley Orgánica 8/2010, de 4 de noviembre, de reforma de la Ley Orgánica 5/1985, de 19 de junio, del Régimen Electoral General, y de la Ley Orgánica 2/1979, de 3 de octubre, del Tribunal Constitucional, Boletín Oficial del Estado, 5 de noviembre de 2010, No 268, pp. 92893-92895. 
España. Acuerdo de 5 de julio de 1990, del Pleno del Tribunal Constitucional, por el que se aprueba el Reglamento de Organización y Personal del Tribunal Constitucional, Boletín Oficial del Estado, 3 de agosto 1990, No 185, pp. $22732-22739$.

España. Acuerdo de 5 de octubre de 1994, del Pleno del Tribunal Consitucional, por el que se modifica parcialmente el Reglamento de Organización y Personal del Tribunal Constitucional, de 5 de julio de 1990, Boletín Oficial del Estado, 21 de octubre 1994, No 252, pp. 32947-32948.

España. Acuerdo de 8 de septiembre de 1999, del Pleno del Tribunal Constitucional, por el que se modifican parcialmente el Reglamento de Organización y Personal del Tribunal Constitucional y el Acuerdo sobre régimen retributivo del personal a su servicio, Boletín Oficial del Estado, 22 de septiembre 1999, No 227, pp. 33857-33858.

España. Acuerdo de 27 de febrero de 2001, del Pleno del Tribunal Constitucional, por el que se modifica parcialmente el Reglamento de Organización y Personal del Tribunal Constitucional, Boletín Oficial del Estado, 7 de marzo 2001, No 57, p. 8605.

España. Acuerdo de 19 de diciembre de 2002, del Pleno del Tribunal Constitucional, por el que se modifica parcialmente el Reglamento de Organización y Personal del Tribunal Constitucional y se aprueba una nueva relación de puestos de trabajo del personal a su servicio, Boletín Oficial del Estado, 24 de diciembre 2002, No 307, pp. $45245-45246$.

España. Acuerdo de 14 de mayo de 2003, del Pleno del Tribunal Constitucional, por el que se modifica parcialmente el Reglamento de Organización y Personal del Tribunal Constitucional, Boletín Oficial del Estado, 24 de mayo 2003, No 124, p. 19954.

España. Acuerdo de 31 de marzo de 2008, del Pleno del Tribunal Constitucional, por el que se modifica parcialmente el Reglamento de Organización y Personal del Tribunal Constitucional, Boletín Oficial del Estado, 2 de abril 2008, No 80, p. 18357.

España. Acuerdo de 28 de abril de 2010, del Pleno del Tribunal Constitucional, por el que se modifica parcialmente el Reglamento de Organización y Personal del Tribunal Constitucional, Boletín Oficial del Estado, 30 de abril 2010, No 105, p. 37779. 